\title{
Implementation of Artificial Neural Network Controller for Double-input Boost Converter
}

\author{
Yonis. M. Buswig ${ }^{1}$, Al-Khalid bin Hj Othman ${ }^{2}$, Norhuzaimin bin $\mathrm{Julai}^{3}$, Sim Sy $\mathrm{Yi}^{4}$, \\ W. M. Utomo ${ }^{5}$, A. J. M. S. Lim \\ ${ }^{1,2,3}$ Deparment of Electrical and Electronic Engineering, Faculty of Engineering, Universiti Malaysia Sarawak, 94300, \\ Kota Samarahan, Malaysia \\ ${ }^{4}$ Department of Electrical Engineering Technology, Faculty of Engineering Technology, \\ ${ }^{5}$ Department of Computer Systems, Faculty of Computer science, University of Narotama Surabaya Indonesia, Surabaya, \\ Indonesia \\ ${ }^{6}$ Department of Infrastructure and Geometric Engineering, Faculty of Civil and Environmental Engineering,
}

\begin{tabular}{l}
\hline Article Info \\
\hline Article history: \\
Received Feb 4, 2018 \\
Revised Apr 22, 2018 \\
Accepted Apr 27, 2018 \\
\hline
\end{tabular}

Keywords:

Artificial Neural Network

(ANN) controller

Boost converter

Double-input power converter

Renewable energy applications

\begin{abstract}
This paper describes the design of an artificial neural network (ANN) control with power sharing control abilities of a new proposed double-input boost power converter (DIBC). The goal of this research is to model and design a high effectiveness and great performance double-input power converter for renewable energy applications. First, an artificial neural network controller design which is flexible versus a variable input voltage resource and variable load (to achieve the line regulation test and load regulation test) is proposed. Lastly, the suggested concept has been validated through experimentally on the laboratory prototype by using DSP TMS320F28335 real-time digital control. The experimental outcomes emphasize the authenticity of the suggested topology, which can be promising a novel topology that includes double-input power converter appropriate for renewable energy application systems.
\end{abstract}

Copyright () 2018 Institute of Advanced Engineering and Science. All rights reserved.

\section{Corresponding Author:}

Yonis. M. Buswig,

Deparment of Electrical and Electronic Engineering, Faculty of Engineering,

Universiti Malaysia Sarawak, 94300, Kota Samarahan, Malaysia.

Email: byonis@unimas.my

\section{INTRODUCTION}

Global warming and the depletion of the non-renewable resource have highlighted the importance of renewable electric power technologies. Coal and fuel electric power generators have significant impacts on world energy consumption and carbon dioxide emissions. Thus, solar array and the wind turbine have become important sources of renewable electric energy. They offer many advantages as a quiet, clean, free, never-ending source and requiring little maintenance. For this reasons, the demand for alternative electric energy sources is increasing each year.

The single input direct current converters are linked to the electrical source like the normal battery, wind turbine, and other resource power with (I-V) characteristic and output port can be joint with direct current in-parallel or in-series [1]-[5]. Thus, diverse power resources can be conjoined either in-parallel [6], [11], [12] or in-series [13]-[15], [21] with the electrical-linked multi-input converters topology. However, the major constraint of the input resource topology linked in-parallel configuration is mandatory of input resource to asymmetric at the same time, one input resource supply power to the electrical load to shun power from the coupling impact. The series connection the input resources are important to supply power at same time. Thus, in-series arrangement, using one power diode, for each input resource enable avert, other input voltage resource to shape the parallel-connections configuration, that the excess number of electronics component [18]-[20]. 
Notwithstanding, these arrangements have feebleness such as costly, massive and intricate in design. As well decrease the effectiveness and thoroughness of the complete system. Thus, the single power converter with multi-input had been proposed [23], superseding the multi-single input converters. Multi-input converter offering simple and extra combined designing well decreasing the value and the systems complication. Furthermore, the effectiveness of energy allocation boosts dependable at the regulator output voltage [5], [6].

Several isolations and non-isolation configuration on multi-input power converters have been introduced in [6]-[17]. The electrical-connected circuits are suited to non-isolation topologies whilst the magnetism-connection circuit related to that isolation configuration. In magnetism-connection circuits, power diversion from resources to electrical load is accomplished by using the flux mechanism and time domain multiplexing [8]. Thus, the requirement of the more surrounding circuit and the transformation requirements performed the magnetism-connection circuits intricate, hugely, and costly as well as rising the circuits parameters dependency [5], [9], [10] while electrical-connected circuits have a modular structure, diminished cost and does not use the transformation method, thence this non-isolation circuits more attractive and highly diminish the issue related with magnetism-connection circuit.

In the past years, the controller for the PWM switching control is restraining to ProportionalIntegral Differential (PID) controller [22]. The controller often implemented to the power converter deu to of the simplicity. But, applied of this control topology to the nonlinear plants of the power converter will afford from the electrical dynamic response of the power converters the output voltage regulations [24].

\section{STRUCTURE OF ARTIFICIAL NEURAL NETWORK CONTROL DESIGN}

In the designing of the artificial neural network controller topology, several pieces of information related to the application are wanted . Substantially, numbers of inputs and outputs neurons for each of layer are similar to numbers of inputs and outputs connection control signals of the designing structure respectively. Design of suggested artificial neural network controller of the proposed multi-input power converter is described in Figure 1.

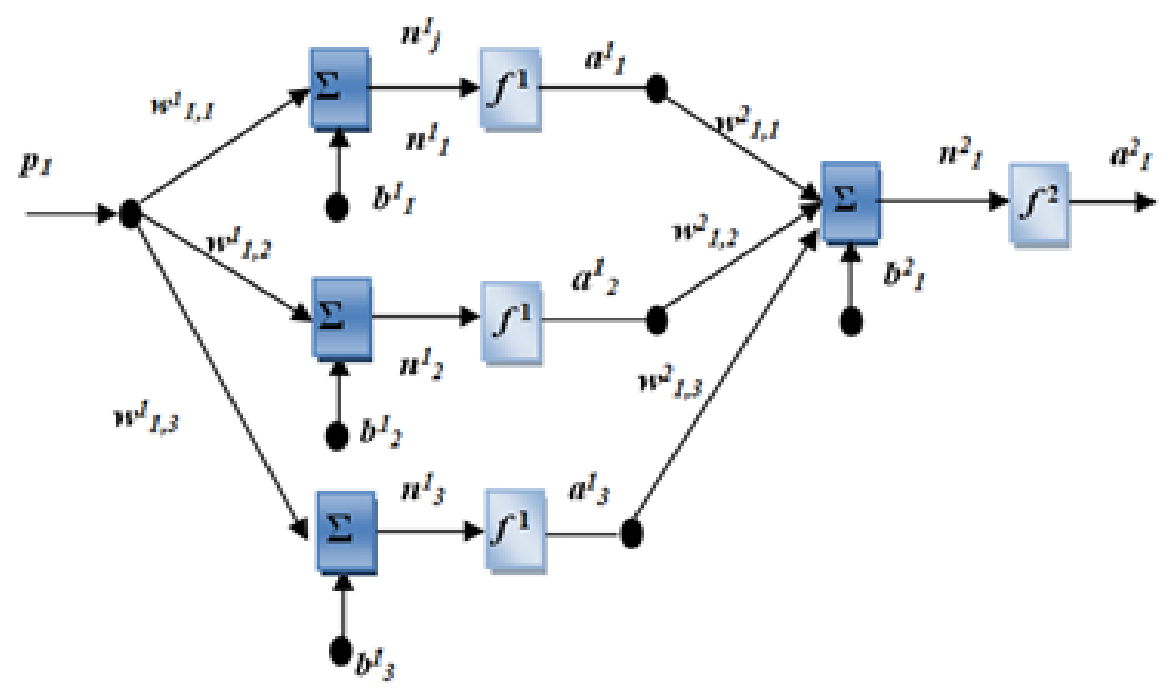

Figure 1. Structure of ANN control topology

Depend on the numbers of (neurons) in each of layer of the suggested artificial neural network controller structure, the proposed network contains a (1-3-1) neurons as a structural design. The input layer has neurons with several inputs.The input neuron represents the error- signal which results from the variation between the desired signal and the actual signal.

The weight $\left(\boldsymbol{j}_{\boldsymbol{t h}}\right)$ and $\left(\boldsymbol{i}_{\boldsymbol{t}}\right)$ neurons at $\left(\boldsymbol{m}_{\boldsymbol{t h}}\right)$ layer is provided by $\left(\boldsymbol{w}_{i j}\right)$, whilst bias variabels of the same layer at $\left(\boldsymbol{i}_{t h}\right)$ neuron is provided by $\left(\boldsymbol{b}_{\boldsymbol{m}}\right)$. The transfer function of the network at $\left(\boldsymbol{t}_{\boldsymbol{t h}}\right)$ neuron in $\left(\boldsymbol{m}_{t h}\right)$ layer is specified as 


$$
n_{i}^{m}=\sum_{j=1}^{s+1} w_{j}^{m} a_{j}^{m-1}+b_{i}^{m}
$$

The represented output represented the function of each neuron at $\left(\boldsymbol{m}_{\boldsymbol{t h}}\right)$ layer is specific by

$$
a_{i}^{m}=f^{m}\left(n_{i}^{m}\right)
$$

$\boldsymbol{f}$ represents the activation function of the neuron. In the structure, the activational function for output layer and hidden layer are unity and a (tangent hyperbolic function) respectively. The activation function is specified as

$$
f^{m}\left(n_{i}^{m}\right)=\frac{2}{1+e^{-2 n_{i}^{\prime \prime}}}-1
$$

For updating processes of the weight and bias variables are specified by

$$
\begin{gathered}
w_{i j}^{m}(k+1)=w_{i j}^{m}(k)-\alpha \frac{\partial F(k)}{\partial w_{i j}^{m}} \\
b_{i}^{m}(k+1)=b_{i}^{m}(k)-\alpha \frac{\partial F(k)}{\partial b_{i}^{m}}
\end{gathered}
$$

Where $: \boldsymbol{k}$ represents the sampling time,

$\alpha$ represents the learning rate,

$\boldsymbol{F}$ represents the performance index function of the network.

When the network structure is modeled, next process is defining the learning model in order to updating the network variables. Basically, in a learning mode of the neural network control, an adequate training data (input-output) mapping data of the application is wanted. Thus, the online learning backpropagation algorithm is developed. The achievement sum of square error is specified as the following equations

$$
\begin{aligned}
& F(k)=\frac{1}{2} \sum_{i} e_{i}^{2}(k) \\
& e_{i}(k)=t_{i}(k)-a_{i}(k)
\end{aligned}
$$

Where, $\left(\boldsymbol{t}_{\boldsymbol{i}}\right)$ represents the target signal

$\left(\boldsymbol{a}_{i}\right)$ represents the output signal on last layer.

The gradient descent of the performance index is specified as the following equation:

$\frac{\partial F}{\partial w_{j j}^{m}}=\frac{\partial F}{\partial n_{j}^{m}} \frac{\partial n_{i}^{m}}{\partial w_{j j}^{m}}$

The sensitivity parameters of the network is specifed as

$s_{j}^{m i}=\frac{\partial F}{\partial n_{j}^{m}}$

$s_{i}^{m}=\frac{\partial F}{\partial a_{i}^{m}} \frac{\partial a_{i}^{m}}{\partial n_{i}^{m}}$

Gradient the transfer function is specific as the following equation: 
$\frac{\partial n_{i}^{m}}{\partial w_{j}^{m}}=a_{i}^{m-1}$

By substitution the equation (9) and (11) into (4) the updating connection parameters is specific by:

$w_{i j}^{m-1}(k+1)=w_{i}^{m-i}(k)-\alpha s_{i}^{m}(k) d_{i}^{m-1}(k)$

With the same technique the updating bias parameters is specific by:

$$
b_{i}^{m-1}(k+1)=b_{i}^{m-i}(k)-\alpha s_{i}^{m}(k)
$$

\section{EXPERIMENTAL ANALYSIS RESULTS}

A prototype of the proposed double-input boost converter has been designed as shown in Figure 2. so as to validated the electrical capacity, efficiency, and performance of the proposed. The proposed converter has been developed with a lower power experimental setup. The generating of switching pulses signals and real-time integrating had been accomplished with DSP TMS320F28335 real time-digital control. The parameters of this double-input power converter are described in Table 1.

Table 1. Parameters of the Designed Power Converter

\begin{tabular}{cc}
\hline Parameters & Value \\
\hline Vin1 & $24 \mathrm{~V}$ \\
Vin2 & $12 \mathrm{~V}$ \\
d1 & $75 \%$ \\
d2 & $75 \%$ \\
d3 & $25 \%$ \\
d4 & $25 \%$ \\
L1 & $8 \mathrm{mH}$ \\
L2 & $8 \mathrm{v}$ \\
C & $470 \mathrm{v}$ \\
$\mathrm{f}$ (S1 \& S2) & $10 \mathrm{kHz}$ \\
$\mathrm{f}$ (S3 \& S4) & $20 \mathrm{kHz}$ \\
VOut & $54 \mathrm{~V}$ \\
$\mathrm{R}$ & $10 \Omega$ \\
\hline
\end{tabular}

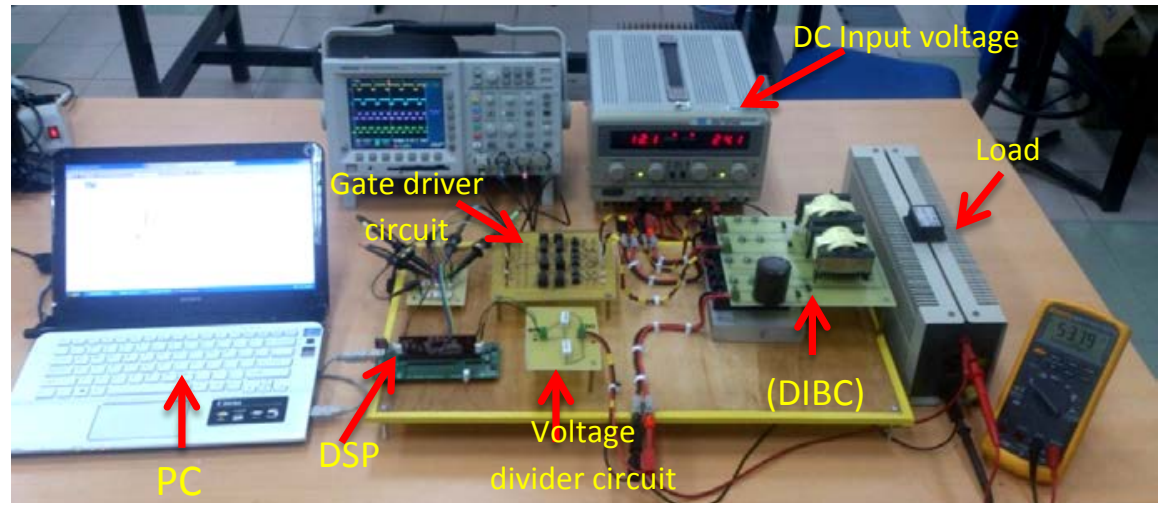

Figure 2. Hardware prototype of the suggested double-input boost power converter

Substantiate the process of open loop double-input power converter operation, suggested control is performed, and various experimental processes are behaving on a closed loop double-input power converter 
operation to examine the execution of control for the line regulations and load regulations test. The outcomes of the experiments for the experimental procedure model in Figure 3 and Figures 4, explain the dynamic range response of closed loop power double-input power converter when a step changing occurs in parameters.

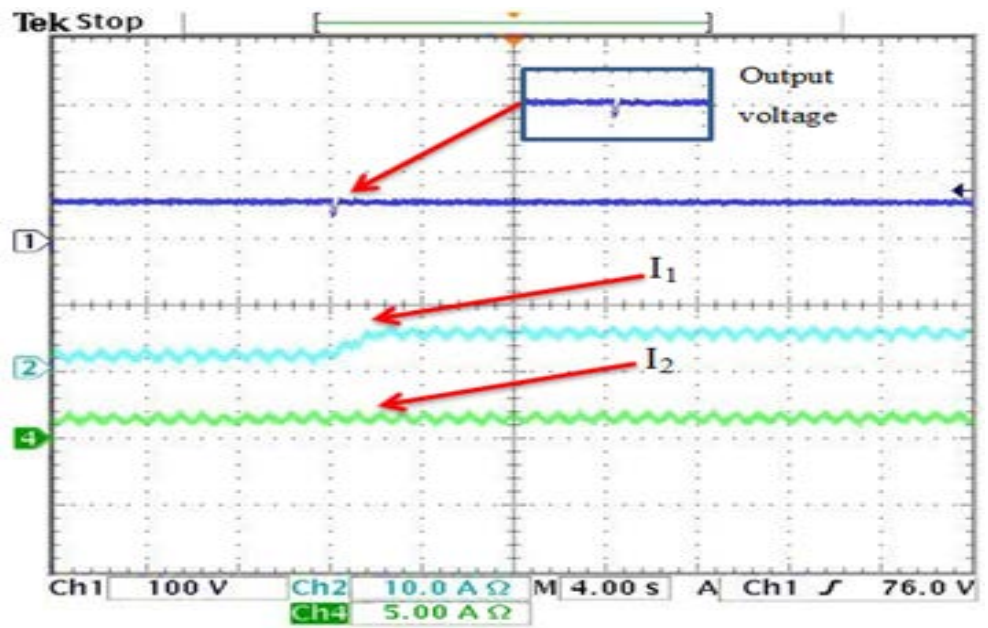

Figure 3. Line regulation: output voltage waveform of the input avarage currents experimental showing dynamic range response of (DIBC) when V1 stepped down the average voltage from $24 \mathrm{~V}$ to $18 \mathrm{~V}$

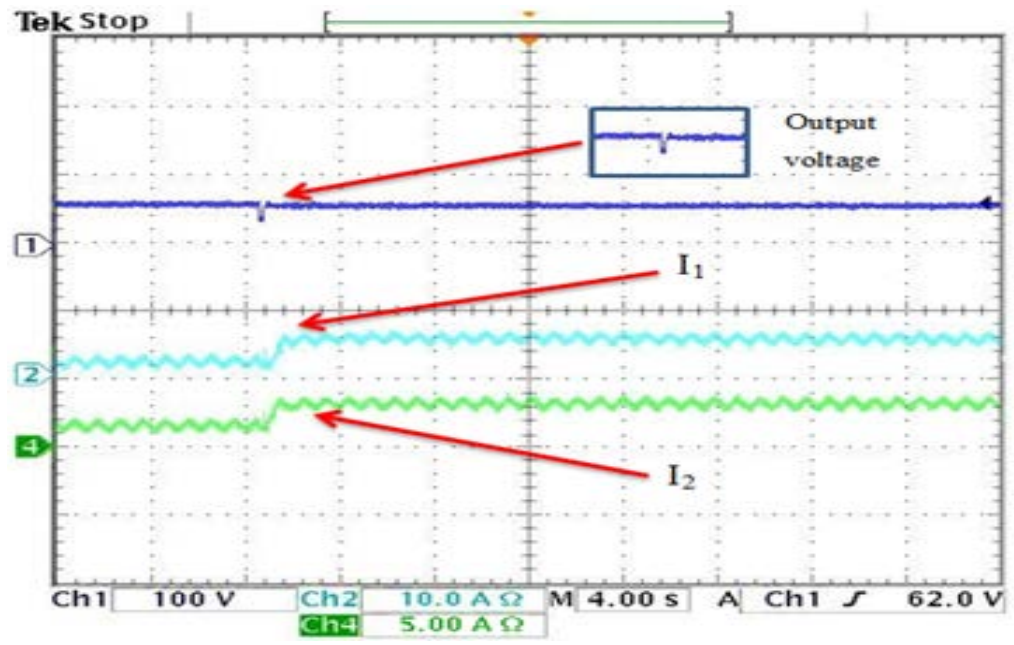

Figure 4. Load regulation: output voltage waveform and average value of input currents experiments results showing the dynamic response of (DIBC) when load stepped-down from $20 \Omega$ to $10 \Omega$

Figure 3; illustrate (line regulation) of closed loop power converter experimental outcomes when first voltage source (V1) is stepped-down from 24 to $18 \mathrm{~V}$. The rate of the energy pulled from both resources and the full outcome energy does not alteration during the operations, consequently the decrease of energy being provided by the first resource due to reducing voltage is recompensed by rising the current pulled from this resource; therefore, as shown in Figure. 3, the current pulled from first resource raised, while the current pulled from the second resource keep fixed. In this situation, the transient dynamic range response in output voltage as shown in above Figure is successful and effective.

Figure 4, presents the load regulation of closed-loop converter experimental outcomes when the load stepped. The output average power is raised, consequently, the input power is raised as well. Given that the proportion of the power pulled from both resources is fixed, the current pulled from both resources are raised 
accordingly. In this situation as in the previous status, the result transient range in the outcome output voltage shown up in above Figure is rather negligible.

\section{CONCLUSION}

A neural network with sharing of the power control for a proposed power converter had been designed and implemented in this paper. The artificial neural network controller model was designed for the proposed double-input converter. The designing control technique has been implemented on a prototype of multi-input boost power converter, and adequate experimental outcomes have been provided to verify the performance of the proposed design. The results showed that the proposed converter is adept for energy variegation from different energy sources. In addition, the proposed artificial neural network controller design is adaptive against input voltage and load disturbances to provide a good line regulation and load regulation dynamic response when the change occurs in parameters.

\section{ACKNOWLEDGMENTS}

The author would like to gratitude and acknowledges the financial support rendered by research and innovation management center (RIMC) UNIMAS through Fundamental Research Grant Scheme FRGS/1/2017/TK10/UNIMAS/03/1, Ministry of Higher Education, Malaysia.

\section{REFERENCES}

[1] Valenciaga, F., Puleston, P.F. Supervisor control for a stand-alone hybrid generation system using wind and photovoltaic energy', IEEE Transactions on Energy Conversion. 2005, 20, (2): 398-405

[2] K PitchaiVijaya, KK Mahapatra. Adaptive-fuzzy controller based shunt active filter for power line conditioners. TELKOMNIKA (Telecommunication, Computing, Electronics and Control). 2011; 9(2): 203-210.

[3] Wang, C., Nehrir, M.H. Power management of a stand-alone wind/ photovoltaic/fuel cell energy system. IEEE Transactions on Energy Conversion. 2008: 23 (3):957-967.

[4] Jiang, W., Fahimi, B. Multiport power electronic interface - concept, modeling, and design. IEEE Transactions on Power Electronics. 2011: 26(7): 1890-1900

[5] Khaligh, A., Cao, J., Lee, Y.-J. A Multiple-Input DC-DC converter topology. IEEE Transactions on Power Electronics. 2009; 24(3):862-868

[6] H Nasution. Development of fuzzy logic control for vehicle air conditioning system. TELKOMNIKA (Telecommunication Computing Electronics and Control). 2008; 6(2): 73-82.

[7] Chen, Y.-M., Liu, Y.-C., Wu, F.-Y. Multi-input DC/DC converter based on the multiwinding transformer for renewable energy applications. IEEE Transactions on Industrial Applications. 2002; 38 (4):1096-1104

[8] Matsuo, H., Lin, W., Kurokawa, F., Shigemizu, T., Watanabe, N. Characteristics of the multiple-input DC/DC converter. IEEE Transactions on Industrial Electronics. 2004; 51(3): 625-631

[9] Zhao, H., Round, S.D., Kolar, J.W. An isolated three-port bidirectional DC-DC converter with decoupled power flow management. IEEE Transactions on Power Electronics. 2008; 23(5):2443-2453

[10] Dobbs, B.G., Chapman, P.L. A multiple-input DC-DC converter. IEEE Transactions on Power Electronics.2003;1 (1):6-9

[11] Gummi, K., Ferdowsi, M. Double-input DC-DC power electronic converters for electric- drive vehicles - topology exploration and synthesis using a single-pole triple-throw switch. IEEE Transactions on Industrial Electronics. 2010; 57(2): 617-623

[12] Chen, Y.-M., Liu, Y.-C., Lin, S.-H. Double-Input PWM DC/DC converter for high-/low- voltage sources. IEEE Transactions on Industrial Electronics.2006; 53(5): 1538-1545

[13] Ahmadi, R., Ferdowsi, M. Double-input converters based on H-bridge cells: derivation, small-signal modeling, and power sharing analysis. IEEE Transactions. On Circuits and System.59 (4):875-888

[14] N Baatar, S Kim. A Thermoelectric Generator Replacing Radiator for Internal Combustion Engine Vehicles. TELKOMNIKA (Telecommunication, Computing, Electronics and Control). 2011; 9(3): 523-530.

[15] Nami, A., Zare, F., Ghosh, A., Blaabjerg, F. Multi-output DC-DC converters based on diode- clamped converters configuration: topology and control strategy. IET Power Electronics. 2010; 3(2): 197-208

[16] Patra, P., Patra, A., Misra, N. A single-inductor multiple-output switcher with simultaneous buck, boost, and inverted outputs. IEEE Transactions on Industrial Electronics. 2012; 27(4):1936-1951

[17] Liu, Y.-C., Chen, Y.-M. A systematic approach to synthesizing multi-input DC-D converters. IEEE Transactions on Industrial Electronics. 2009; 24(1):116-127

[18] Ahmadi, R.; Zargarzadeh, H.; Ferdowsi, M. Nonlinear Power Sharing Controller for a Double-Input H-BridgeBased Buckboost-Buckboost Converter. IEEE Transactions on Power Electronics. 2013; 5(28):2402-2414.

[19] Li, Y., Ruan, X., Yang, D., Liu, F., Tse, C.K. Synthesis of multiple-input DC/DC Converters. IEEE Transactions on Power Electronics. 2010; 25(9): 2372-2385

[20] Kwasinski, A. Identification of feasible topologies for multiple-input DC- DC converters. IEEE Transactions on Power Electronics. 2009; 24(3);856-861 
[21] Chih-Lung, S., Shih-Hsueh, Y. Multi-Input Converter with MPPT Feature for Wind-PV Power Geneartion System. International Journal of Photoenergy.2013; 13 pages.

[22] Ramkumar, P. V., Kalavathi, M. S. Fractional Order PID Controlled Interleaved Boost converter Fed Shunt Active Filter System. International Journal of Power Electronics and Drive Systems (IJPEDS). 2018; 9(1): 126-138.

[23] SULAKE, N. R., \& Ch, S. B. Integration of Reversing Voltage Multilevel Inverter Topology with High Voltage Gain boost Converter for Distributed Generation. International Journal of Power Electronics and Drive Systems (IJPEDS). 2018; 9(1): 210-219.]

[24] RAO, H. G., Mudliyar, K., \& MALA, R. A New Small-Signal AC Model and Closed Loop Control of a Three Phase Interleaved Boost Converter. International Journal of Power Electronics and Drive Systems (IJPEDS).2018; 9(1): 240-251 